\title{
Optimum Currency Areas Theory: An Empirical Application to Turkey
}

\section{Itir Ozer, Ibrahim Ozkan, Okan H. Aktan}

\begin{abstract}
This study aims to assess Turkey's position relative to European countries with respect to the optimum currency areas (OCA) criteria, taking Germany as the center country and employing Mahalanobis distance as a similarity measure. To this end, we followed a novel approach in the application of Hodrick-Prescott and Baxter-King filters to the industrial production series and the real interest rates under three cases. We then computed OCA similarity indices, calculated countries' similarities with respect to Germany and their nearest neighbors, and compared the results. Our results show that Turkey is the second furthest neighbor country to Germany after Croatia in the first two cases. However, Turkey is the third furthest country to Germany after Norway and Romania in the third case
\end{abstract}

Key words: Optimum Currency Areas Theory, Turkey, Rate

\section{JEL : F15 DOI: 10.2478/v10033-007-0008-y}

\section{Introduction}

Optimum currency areas (OCA) theory aims to define the optimal geographic domain of a single currency. It was developed by the seminal contributions of Mundell (1961), McKinnon (1963), and Kenen (1969). OCA theory can be examined in three phases. The first is the pioneering phase of the 1960s and early 1970s, followed by the reconciliation phase of the 1970s. In the third phase, OCA theory was reassessed and operationalized through empirical studies beginning in the 1980s.

Empirical studies can be classified as econometric studies, or studies that employ the techniques of pattern recognition. Eichengreen and Bayoumi (1996), Artis and Zhang (2001), Artis and Zhang (2002), Boreiko (2002), Komárek, Cech and Horváth (2003), and Kozluk (2005) applied the techniques of pattern recognition to a set of variables suggested by the OCA theory. Pattern recognition is the act of taking raw data (which are based on a priori information or statistical information formed from patterns) and taking an action based on the "category" of the pattern (Duda, Hart, and Stork 2000, p. 15).

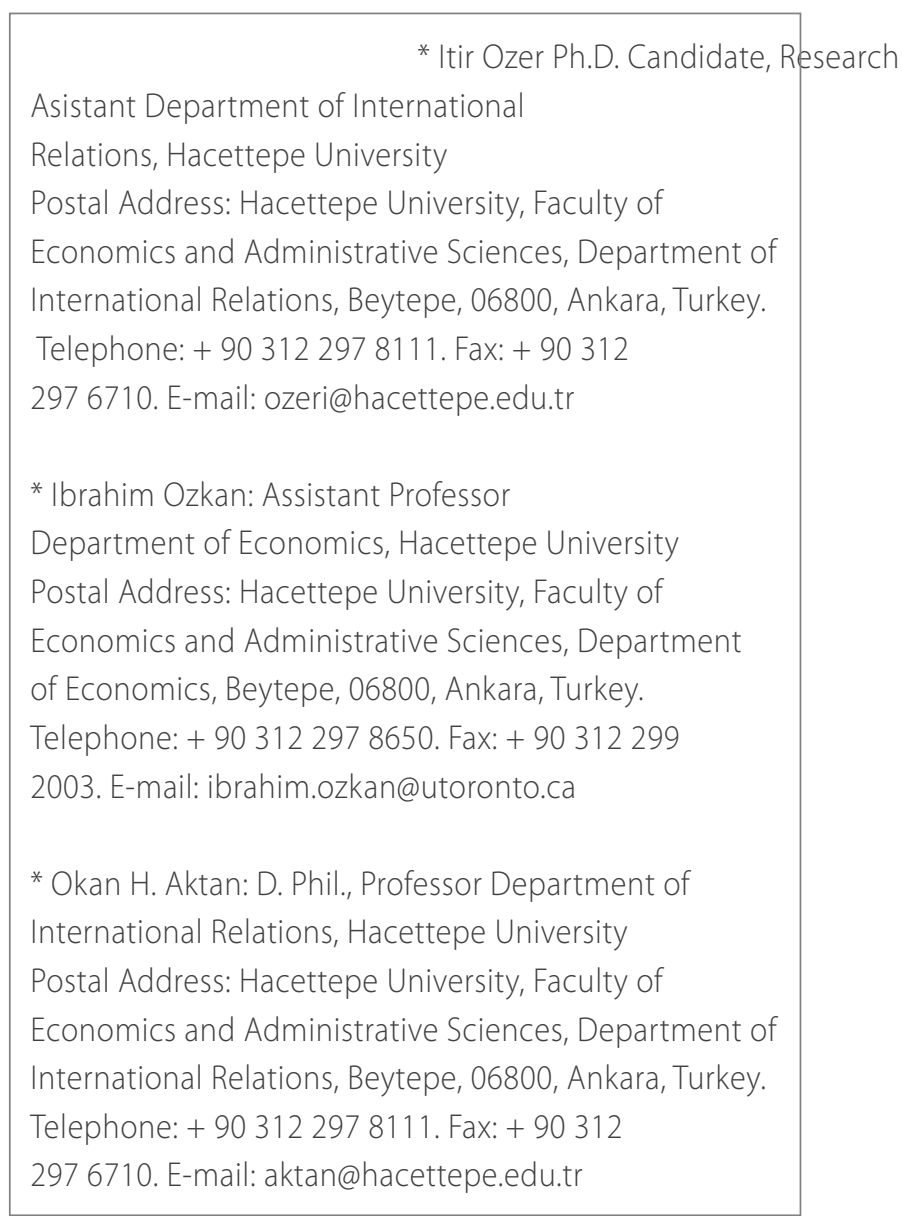


This paper attempts to assess Turkey's position relative to twenty-four European countries with respect to the OCA criteria, taking Germany as the center country. The nearer (more similar) a country is to Germany in terms of OCA criteria, the more suitable it is for this country to be a part of the currency area centered around Germany. Synchronization in business cycles, volatility in the real exchange rates, synchronization in the real interest rates, the degree of trade integration, and convergence of inflation are the OCA criteria included in our analysis, following Artis and Zhang (2001), Artis and Zhang (2002), Boreiko (2002), and Kozluk (2005). Canada and Japan were inlcuded as the control group countries in order to determine whether they can be sharply distinguished from the European countries. We have constructed our analysis under three cases in which we have applied the Hodrick-Prescott $(\mathrm{H}-\mathrm{P})$ and the Baxter-King (B-K) filters to industrial production series and real interest rates. The application of $\mathrm{H}-\mathrm{P}$ and $\mathrm{B}-\mathrm{K}$ filters to industrial production series and the real interest rates as used in this paper is a novel approach in this area. We then employed Mahalanobis distance as a similarity measure and computed OCA similarity indices. Afterwards, in all three cases we calculated Turkey's and each European country's similarity with respect to Germany, presented the countries' nearest neighbors for Case III, and compared the results of the application of different filtering techniques, as they produce different results for the same data. In order to assess the relative position of the control group, we carried out principal component analysis. The remaining of the paper is as follows. In Section 2, we briefly discuss data and methodology. In Section 3, we provide the results. Section 4 concludes our paper.

\section{Data and Methodology}

Austria, Belgium, Croatia, Cyprus, Czech Republic, Denmark, Finland, France, Germany, Greece, Hungary, Ireland, Italy, Luxembourg, the Netherlands, Norway, Poland, Portugal, Romania, Slovak Republic, Slovenia, Spain, Sweden, Turkey, and the UK are the countries in the sample. Canada and Japan were included as control group countries.

\subsection{Filtering Techniques and OCA Criteria}

OCA studies carried out with the techniques of pattern recognition generally assume that Germany is the center country (Artis and Zhang (2001), Artis and Zhang (2002), Boreiko
(2002), and Kozluk (2005)). The criteria widely used in these studies are synchronization in business cycles, volatility in the real exchange rates, synchronization in the real interest rates, the degree of trade integration and convergence of inflation. We included the same criteria in our analysis. Artis and Zhang (2001), Artis and Zhang (2002), and Kozluk (2005) included labor market flexibility as another OCA criterion in their analysis. However, because of the lack of data for Turkey and most of the countries, we excluded this criterion from our analysis.

In OCA theory literature, for the calculations of two of the criteria synchronization in business cycles and synchronization in the real interest rates, monthly industrial production series and monthly real interest rates have been detrended with the application of the Hodrick-Prescott (H-P) filter (Hodrick and Prescott (1997)). In some atheoretic studies of business cycles (Murray (2003) and Takaya (2005)), the Baxter-King (B-K) filter has been used to obtain the cyclical components of industrial production series (Baxter and King (1999)). Since the application of different filtering techniques produce different results for the same data, we employed both the H-P and the B-K filtering techniques in our analysis.

Hodrick-Prescott (H-P)Filter. The H-P filter decomposes a time series, $\gamma_{t}$, into an additive cyclical component, $\gamma^{c}{ }_{t^{\prime}}$ and a growth component, $\gamma^{g}$

$$
y_{t}=y_{t}^{\mathcal{E}}+y_{t}^{c}
$$

Applying the $\mathrm{H}$-P filter involves minimizing the variance of the cyclical component, $\gamma^{c}$, subject to a penalty for the variation in the second difference of the growth component, $Y^{g}{ }_{t}$

$$
\left\{v_{\&}^{t}\right\}_{t-0}^{T+1}=\operatorname{argmin} \sum_{t=1}^{T}\left[\left(y-y_{t}^{g}\right)^{2}+\lambda\left[\left(y_{t+1}^{g}-y_{t}^{g}\right)-\left(y_{t}^{g}-y_{t-1}^{g}\right)\right]^{2}\right]
$$

where $\lambda$, the smoothing parameter, penalizes the variability in the growth component. The larger the value of $\lambda$, the smoother the growth component. As $\lambda$ approaches infinity, the growth component corresponds to a linear time trend (Guay and St-Amant, 1997, p. 2-3).

There are two different approaches to the question of choosing the smoothing parameter. The first approach is the free choice of smoothing parameter. In this approach, the smoothing parameter is usually fixed in an arbitrary way (Schlicht 2005, p. 99). In the OCA studies, Artis and Zhang (2001), Artis and Zhang (2002), and Boreiko (2003) have set 
the smoothing parameter's value at 50,000 for relatively noisy industrial production series and real interest rates, whereas Kozluk (2005) has used 14,400 for the smoothing parameter.

The other approach is to find the optimum smoothing parameter by statistical methods, i.e., an automatic estimation method. In this approach, the optimum smoothing parameters are assigned values, which are calculated based on the nature of the time series data (Dermoune, Djehiche and Rahmania, 2006, p. 2-4) following Schlicht (2005). Let $\mathrm{x}=\left(\mathrm{x}_{1}, \mathrm{x}_{2}, \ldots, \mathrm{x}_{\mathrm{T}}\right)$ be a non-stationary time series with trend and cyclical components. Then, consistent estimator, $\lambda$, can be written as:

$$
\hat{\lambda}=\max \left\{0-\frac{1}{4}\left(\frac{\frac{3}{2}+(T-3) \sum_{j-1}^{T-2} P x(j)^{2}}{(T-2) \sum_{j-1}^{T-3} P x(j) P x(j+1)}\right)^{-1}\right\}
$$

where, $\mathrm{P}$ matrix is:

$$
P=\left(\begin{array}{rrrrrr}
1 & -2 & 1 & \ldots & \ldots & 0 \\
1 & 1 & -2 & 1 & \ldots & 0 \\
& \ldots & \ldots & \ldots & \ldots & \\
0 & \ldots & \ldots & 1 & -2 & 1
\end{array}\right)
$$

Baxter-King (B-K) Filter. The B-K filter computes the cyclical components, $\left\{y_{t}\right\}_{t=1}^{T}$ of the given time series, $\left\{x_{t}\right\}_{t=1}^{T}$. It is an approximation of an ideal bandpass filter, which passes only the signals that have periods between selected lower and upper periods. It relies on the use of a symmetrix finite odd-order $M=2 K+1$ moving average so that:

$$
\hat{y}_{t}=\sum_{n=-K}^{K} \hat{B}_{n} x_{t-n}=\hat{B}_{0} x_{t}+\sum_{n=1}^{K} \hat{B}_{n}\left(x_{t-n}+x_{t+n}\right)
$$

A sequence $\hat{B}_{t, j}$ that minimizes the mean squared error between, $y_{t} y_{t^{\prime}}$ given by:

$$
\left\{\hat{B}_{t, j}\right\}=\arg \min E\left\{\left(y_{t}-\hat{y}_{t}\right)^{2}\right\}
$$

The set of $M$ coefficients $\hat{B}_{j}$ is obtained by applying condition (6) to the ideal filte $r$ coefficients imposing symmetry and stationary restrictions. The solution takes the form:

$$
\hat{B}_{j}=B_{j}-1 / M \sum_{n=-K}^{R} B_{n}
$$

Filtering in time domain using moving averages involves the loss of $2 K$ data values. In Baxter and King (1999), a value of $K=12$ for the passband $[1.5,8]$ years is found to be basically equivalent to higher values, such as 16 or 20 .

In this study, we constructed our analysis under three cases in order to determine the differences in the results when different filtering techniques are employed. In Case I, we applied the H-P filter to the industrial production series and the real interest rates, in which the smothing parameter is fixed at 50,000 following Artis and Zhang (2001), Artis and Zhang (2002), and Boreiko (2003). In Case II, we H-P filtered the industrial production series as in Case I, since industrial production series involve trend. As real interest rates are not expected to follow a long-term trend, we have employed the H-P filter to the real interest rates with the estimated smoothing parameters. The smoothing parameters for the countries in the sample for synchronization in the real interest rates are given in Table 1.

\begin{tabular}{|l|l|l|l|}
\hline Austria & 0.12 & Netherlands & 0.09 \\
\hline Belgium & 0.22 & Norway & 0.49 \\
\hline Croatia & 0.47 & Poland & 1.4 \\
\hline Cyprus & 0.8 & Portugal & 0.32 \\
\hline Czech Republic & 0.07 & Romania & 0.37 \\
\hline Denmark & 0.98 & Slovak Republic & 3.21 \\
\hline Finland & 0.13 & Slovenia & 0.69 \\
\hline France & 0.12 & Spain & 0.87 \\
\hline Germany & 1.21 & Sweden & 0.11 \\
\hline Greece & 0.15 & Turkey & $\mathbf{1 . 1}$ \\
\hline Hungary & 0.22 & United Kingdom & 0.1 \\
\hline Ireland & 0.15 & Canada & 0.94 \\
\hline Italy & 0.06 & Japan & 0.27 \\
\hline Luxembourg & 0.18 & \\
\hline
\end{tabular}

Table 1.

The Smoothing Parameters Assigned by the Automatic Estimation for the Countries in the Sample for Synchronization in the Real Interest Rates

In Case III, we employed the Baxter-King (B-K) filter to both the industrial production series and the real interest rates with a lower period of 13 and an upper period of 86 following the study of Burns and Mitchell (1946). These three cases are shown in Table 2.

\begin{tabular}{|l|l|l|l|}
\hline & Case I & Case II & Case III \\
\hline Industrial Production Series & H-P Filter, $\lambda=50,000$ & H-P Filter, $\lambda=50,000$ & B-K Filter \\
\hline Real Interest Rates & H-P Filter, $\lambda=50,000$ & H-P Filter, $\lambda$ automatic estimation & B-K Filter \\
\hline
\end{tabular}

Table 2.

The Three Cases in which Different Filtering Techniques are Applied to

Industrial Production Series and the Real Interest Rates 
OCA Criteria. In this study, OCA variables have been computed as follows:

1) Synchronization of business cycles has been represented by the cross-correlation of the cyclical components of the deseasonalized industrial production series. The cross-correlations were measured for all the countries in the sample with reference to Germany. Since correlation results in values between -1 and +1 inclusive, we subtracted correlation values from one, so the new values are between zero and two. Zero represents perfect positive correlation, and two represents a perfect negative correlation. We used a distance measure as a similarity measure. Similarly, in order to have a 0 in distance value for perfect correlation, we subtracted correlation values from 1. Therefore, perfect correlation should result in a 0 distance value.

2) Volatility in the real exchange rates was represented by the standard deviation of the log-difference of real bilateral DM exchange rates before 1999. After 1999, the Euro has been used instead of DM for exchange rates. Real exchange rates were obtained by deflating nominal rates by relative wholesale (producer) price indices. For Portugal, we have used the consumer price index because of lack of data.

\section{3) Synchronization in the real interest rates was represented} by the cross-correlation of the cyclical components of the real interest rate cycle of a country with that in Germany. Real interest rates were obtained by deflating short-term nominal rates by consumer price indices. Cross-correlations were measured for all the countries in the sample with reference to Germany, and again the values were set between zero and two.

4) The degree of trade integration was measured by $\left(x_{i}^{E-\S}+m_{i}^{E-8}\right)\left(x_{i}+m_{i}\right) \quad$ where $x_{i}$ and mi are exports and $m_{i}$ imports (of goods) of country i, respectively, and superscript EU-25 represents European Union countries as of May 2004.

5) Convergence of inflation was measured by $e_{i}-e_{g^{\prime}}$ where $e_{i}$ and eg are the rates of inflation in country $i$ and Germany, respectively. The calculated values of the OCA variables for each country are given in Table 3 for Case I.

In Case I, Turkey's synchronization of business cycles with Germany had a value of 0.5966 . The cross-correlation of the cyclical components of industrial production series between Germany and Turkey are given in Figure 1, whereas the cyclical components of the industrial production series of Germany and Turkey are given in Figure 2.
Figure 1 shows lagged correlation of the series used in the synchronization of business cycles. Turkey's business cycle followed Germany's business cycle with an average lag of four months. As can be seen in Table 3, the Netherlands, Ireland, Slovak Republic, Norway, Cyprus, Romania, Czech Republic, Croatia and Portugal's synchronization of business cycles with Germany were also low. Turkey's synchronization of business cycles with Germany was relatively better than these countries. However, Austria, Hungary, Finland, Belgium, Slovenia, the United Kingdom, Greece, Poland,

\begin{tabular}{|c|c|c|c|c|c|}
\hline & 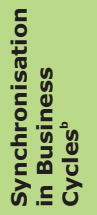 & 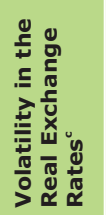 & 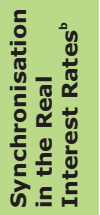 & 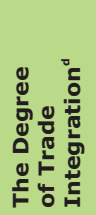 & 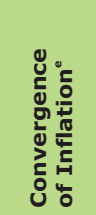 \\
\hline Austria & 0.0965 & 0.0046 & 0.5336 & 76.38 & 0.3436 \\
\hline Belgium & 0.2821 & 0.0121 & 0.7062 & 75.52 & 0.8296 \\
\hline Croatia & 0.9736 & 0.0253 & 1.5117 & 67.49 & 1.3846 \\
\hline Cyprus & 0.8874 & 0.0047 & 0.5391 & 63.82 & 0.6046 \\
\hline Czech Republic & 0.9351 & 0.0129 & 0.7322 & 80.03 & -0.1080 \\
\hline Denmark & 0.4276 & 0.0046 & 0.0817 & 70.49 & -0.1454 \\
\hline Finland & 0.2459 & 0.0044 & 0.6910 & 62.00 & -1.0923 \\
\hline France & 0.4427 & 0.0028 & 0.6755 & 66.83 & -0.2098 \\
\hline Greece & 0.3882 & 0.0047 & 0.7480 & 57.33 & 1.6073 \\
\hline Hungary & 0.1536 & 0.0206 & 1.1266 & 75.27 & 1.5975 \\
\hline Ireland & 0.6647 & 0.0046 & 0.7156 & 62.75 & 0.4617 \\
\hline Italy & 0.4642 & 0.0031 & 0.1487 & 59.61 & 0.0313 \\
\hline Luxembourg & 0.5957 & 0.0111 & 0.4748 & 81.54 & 0.5360 \\
\hline Netherlands & 0.6107 & 0.0042 & 0.6878 & 66.98 & -0.2906 \\
\hline Norway & 0.7397 & 0.0342 & 0.4395 & 75.46 & -0.4319 \\
\hline Poland & 0.3994 & 0.0261 & 0.2802 & 76.36 & 0.1528 \\
\hline Portugal & 1.1110 & 0.0053 & 0.7600 & 78.20 & 0.3397 \\
\hline Romania & 0.9328 & 0.0338 & 0.6828 & 71.61 & 7.0354 \\
\hline Slovak Republic & 0.6833 & 0.0145 & 1.3815 & 83.13 & 0.7549 \\
\hline Slovenia & 0.3025 & 0.0145 & 0.7545 & 74.16 & 0.5250 \\
\hline Spain & 0.5056 & 0.0033 & 0.0715 & 69.25 & 1.4138 \\
\hline Sweden & 0.4373 & 0.0123 & 0.3648 & 67.49 & -1.5007 \\
\hline Turkey & 0.5966 & 0.0672 & 0.7215 & 49.81 & 6.2252 \\
\hline United Kingdom & 0.3170 & 0.0161 & 0.8902 & 53.38 & 0.8768 \\
\hline Canada & 0.3371 & 0.0241 & 0.5195 & 8.38 & 0.2802 \\
\hline Japan & 0.3931 & 0.0252 & 1.0793 & 14.43 & -2.2271 \\
\hline
\end{tabular}

Table 3.

OCA Criteria ${ }^{a}$, Case I

OCA criteria values for Germany are not given in Table 3 since Germany is the center country. For Germany, the only variable

that is different from zero in value is the degree of trade

integration and it is equal to 62.96

${ }^{b}$ Values are between zero and two, where zero represents perfect synchronization.

"Volatility in the real exchange rates has been calculated for

the values after January 1999.

${ }^{d}$ Degree of trade integration are 2004 data.

Convergence of inflation are 2005 data. 
Denmark, Sweden, France, Italy, and Spain's synchronization of business cycles with Germany were better than Turkey's, whereas Luxembourg has a synchronization value of 0.5957 which was slightly better than Turkey's.

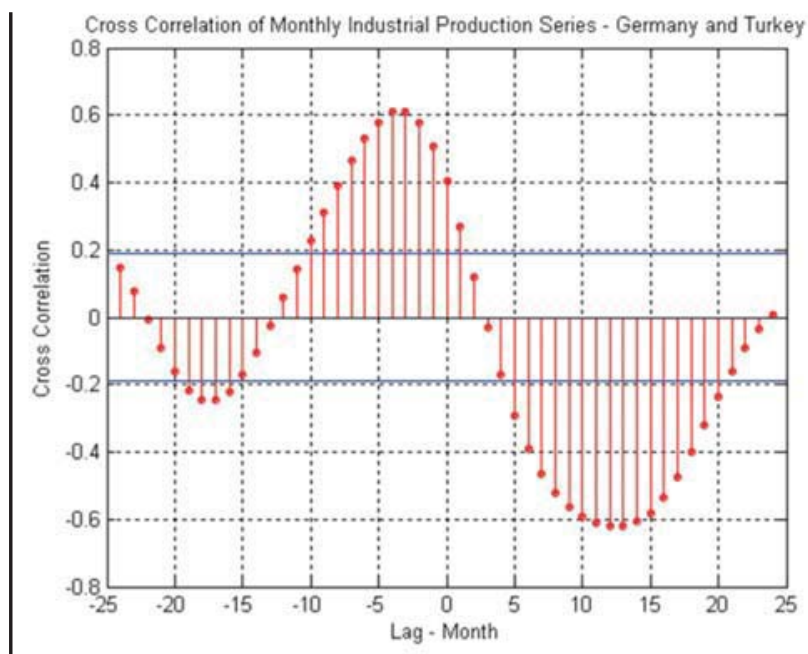

Figure 1

Case I: Cross-correlation of Industrial

Production Series of Germany and Turkey

Detrended Cyclical Components of Monthly Industrial Production Series - Germany and Turkey

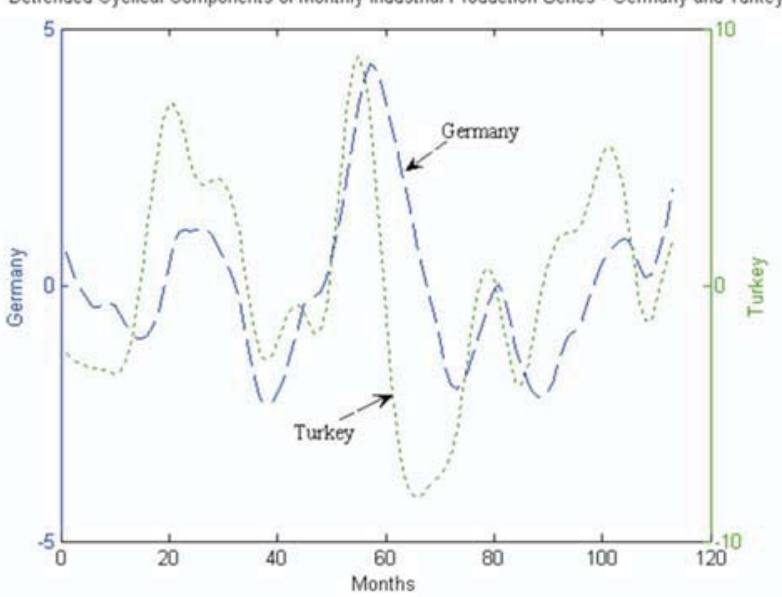

Figure 2.

Case I: Cyclical Components of Industrial

Production Series of Germany and Turkey

The volatility of the real New Turkish Lira had the highest value in the sample. This can be explained by the fact that Turkey experienced a currency crisis in February 2001 and a long history of high inflationary periods. We did not eliminate the high volatility of the Turkish Lira in 2001 caused by the currency crisis; therefore the high volatility of the Turkish Lira was expected in the results. When we treated big deviations observed during the currency crisis as outliers, we found better values. For example, when the ten-month period between February 2001 and December 2001 was excluded from the analysis, volatility of the real Turkish Lira became 0.032980 until February 2001, and 0.049919 after
December 2001, whereas volatility of the real Turkish Lira between February 2001 and December 2001 had a value of 0.12692 , which is quite high. This high volatility of the real Turkish lira shows the effect of the currency crisis in February 2001. For Turkey, we included this period in order to make a realistic analysis. However, it should be noted that this currency crisis adversely affected both the volatility of the real Turkish Lira and Turkey's real interest rate snychronization in our analysis.

Turkey's real interest rate synchronization with Germany had a value of 0.7215 . This value was better than Czech Republic, Greece, Slovenia, Portugal, United Kingdom, Hungary, Slovak Republic and Croatia's synchronizations of the real interest rates with Germany, but worse than those of Spain, Denmark, Italy, Poland, Sweden, Norway, Luxembourg, Austria, Cyprus, France, and Romania, Netherlands,

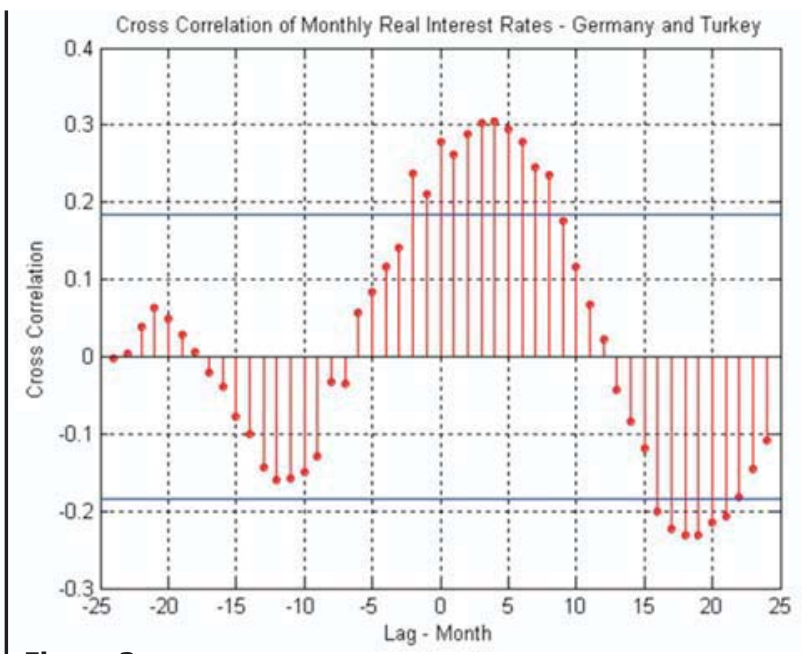

Figure 3.

Case I: Cross-correlation of Real Interest

Rates of Germany and Turkey

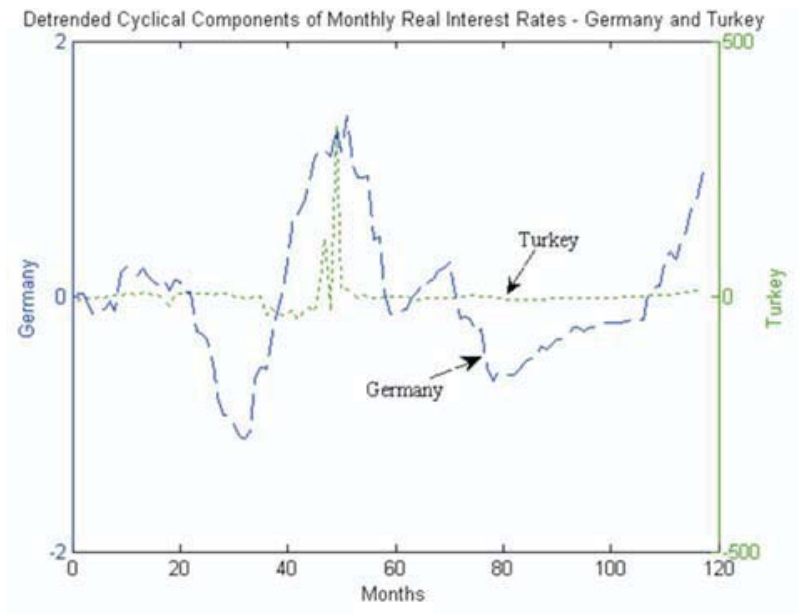

Figure 4.

Case I: Cyclical Components of Real

Interest Rates of Germany and Turkey 
Finland, Belgium, and Ireland. The cross-correlation of real interest rates of Germany and Turkey are given in Figure 3, whereas cyclical components of the real interest rates of Germany and Turkey are given in Figure 4.

In Figure 3, the highest cross-correlation value of the real interest rates of Germany and Turkey was measured at 4 lags.

According to Table 3, Turkey had the lowest degree of trade integration (excluding Japan and Canada) and had the second worst convergence of inflation value after Romania when compared to the other European countries.
Table 4 shows the calculated values of the OCA variables for Cases II and III.

In Case II, Turkey's real interest rate synchronization with Germany improved and became 0.4547 compared to Case I (0.7215). Besides, compared to Case I, the Netherlands, France, Belgium, Romania, Italy, Finland, and Ireland's synchronizations of the real interest rates with Germany worsened; these countries' synchronization values were worse than Turkey's. Cyclical components of real interest rates of Germany and Turkey which improved in Case II compared to Case I are given in Figure 5.

\begin{tabular}{|c|c|c|c|c|c|c|c|}
\hline & \multicolumn{2}{|c|}{ Case II } & \multicolumn{2}{|c|}{ Case III } & \multirow[b]{2}{*}{ 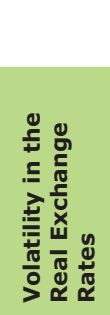 } & \multirow[b]{2}{*}{ 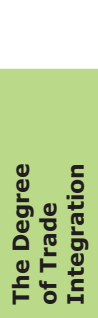 } & \multirow[b]{2}{*}{ 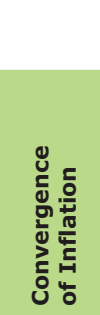 } \\
\hline & 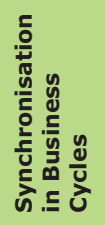 & 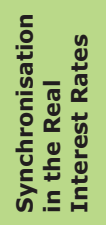 & 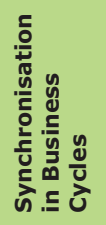 & 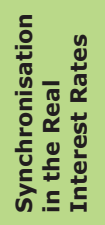 & & & \\
\hline Austria & 0.0965 & 0.3633 & 0.1666 & 0.8889 & 0.0046 & 76.38 & 0.3436 \\
\hline Belgium & 0.2821 & 0.5183 & 0.2679 & 1.1420 & 0.0121 & 75.52 & 0.8296 \\
\hline Croatia & 0.9736 & 1.6042 & 0.6137 & 1.5185 & 0.0253 & 67.49 & 1.3846 \\
\hline Cyprus & 0.8874 & 0.4384 & 0.9908 & 0.3985 & 0.0047 & 63.82 & 0.6046 \\
\hline Czech Republic & 0.9351 & 1.2068 & 0.5229 & 0.5238 & 0.0129 & 80.03 & -0.1080 \\
\hline Denmark & 0.4276 & 0.0497 & 0.3813 & 0.0784 & 0.0046 & 70.49 & -0.1454 \\
\hline Finland & 0.2459 & 0.5648 & 0.2638 & 1.0970 & 0.0044 & 62.00 & -1.0923 \\
\hline France & 0.4427 & 0.5049 & 0.6445 & 1.1125 & 0.0028 & 66.83 & -0.2098 \\
\hline Greece & 0.3882 & 1.1608 & 0.3918 & 0.9497 & 0.0047 & 57.33 & 1.6073 \\
\hline Hungary & 0.1536 & 1.4870 & 0.2356 & 0.9508 & 0.0206 & 75.27 & 1.5975 \\
\hline Ireland & 0.6647 & 0.6415 & 0.6387 & 1.1186 & 0.0046 & 62.75 & 0.4617 \\
\hline Italy & 0.4642 & 0.5366 & 0.5228 & 0.1182 & 0.0031 & 59.61 & 0.0313 \\
\hline Luxembourg & 0.5957 & 0.2620 & 0.7352 & 0.8319 & 0.0111 & 81.54 & 0.5360 \\
\hline Netherlands & 0.6107 & 0.4927 & 0.6992 & 1.1388 & 0.0042 & 66.98 & -0.2906 \\
\hline Norway & 0.7397 & 0.2538 & 0.8497 & 0.7174 & 0.0342 & 75.46 & -0.4319 \\
\hline Poland & 0.3994 & 0.3448 & 0.3982 & 0.3252 & 0.0261 & 76.36 & 0.1528 \\
\hline Portugal & 1.1110 & 0.5307 & 0.9859 & 1.2249 & 0.0053 & 78.20 & 0.3397 \\
\hline Romania & 0.9328 & 0.5271 & 0.9158 & 1.0528 & 0.0338 & 71.61 & 7.0354 \\
\hline Slovak Republic & 0.6833 & 1.3264 & 0.2643 & 1.4626 & 0.0145 & 83.13 & 0.7549 \\
\hline Slovenia & 0.3025 & 0.8753 & 0.3463 & 0.9651 & 0.0145 & 74.16 & 0.5250 \\
\hline Spain & 0.5056 & 0.2794 & 0.5619 & 0.0207 & 0.0033 & 69.25 & 1.4138 \\
\hline Sweden & 0.4373 & 0.3722 & 0.5813 & 0.3213 & 0.0123 & 67.49 & -1.5007 \\
\hline Turkey & 0.5966 & 0.4547 & 0.4498 & 0.6090 & 0.0672 & 49.81 & 6.2252 \\
\hline United Kingdom & 0.3170 & 1.0504 & 0.4456 & 1.1981 & 0.0161 & 53.38 & 0.8768 \\
\hline Canada & 0.3371 & 0.4975 & 0.3641 & 0.2441 & 0.0241 & 8.38 & 0.2802 \\
\hline Japan & 0.3931 & 1.0198 & 0.4027 & 1.3631 & 0.0252 & 14.43 & -2.2271 \\
\hline
\end{tabular}

Table 4

OCA criteria, Cases II and III 


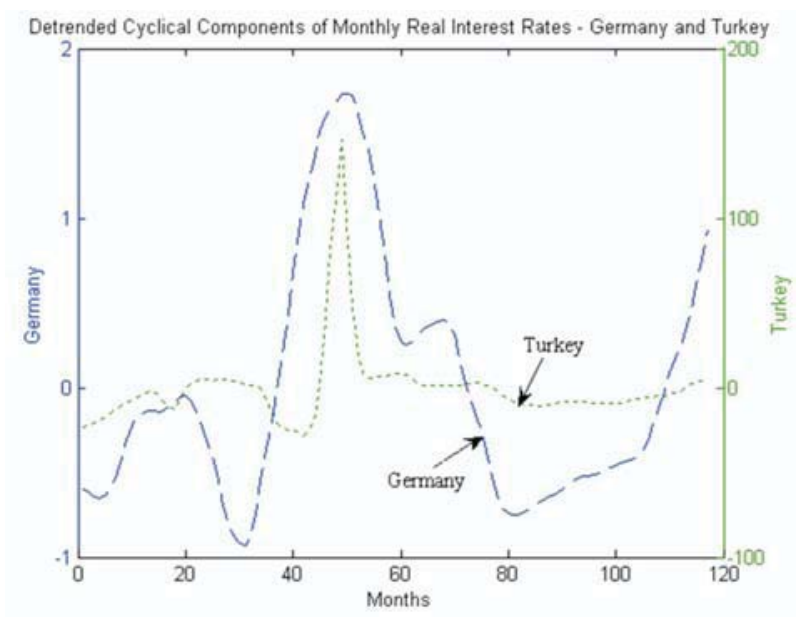

Figure 5.

Case II: Cyclical Components of Real

Interest Rates of Germany and Turkey

In Case III, Turkey's synchronization of business cycles with Germany improves and becomes 0.4498 compared to Cases I and II (0.5966). Besides, Slovak Republic's synchronization of business cycles with Germany improves and becomes better than Turkey's compared to Cases I and II, whereas Italy, Spain, Sweden, France, and Luxembourg's synchronizations of business cycles with Germany worsen and become worse than Turkey's compared to Cases I and II. Cyclical components of the industrial production series of Germany and Turkey which have improved in Case III compared to Cases I and II are given in Figure 6.

In Case III, Turkey's real interest rate synchronization with Germany became 0.6090 . This synchronization value was better than Case I (0.7215) but worse than Case II (0.4547). When Cases I and III are compared for other countries in the sample, it was observed that the Czech Republic's real interest rate synchronization with Germany improved in

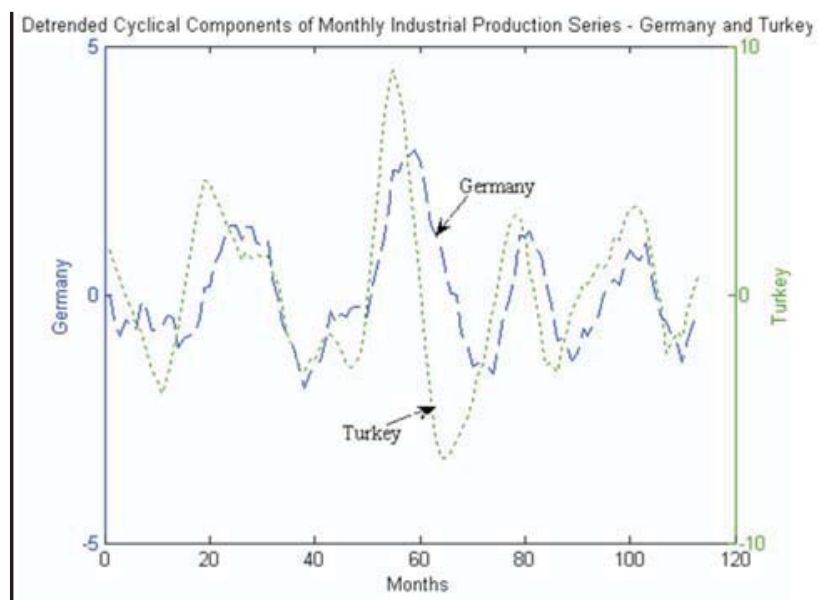

Figure 6.

Case III: Cyclical Components of

Industrial Production Series of Germany and Turkey
Case III and became better than Turkey's, whereas Norway, Luxembourg, Austria, Romania, Finland, France, Ireland, Netherlands, and Belgium's real interest rate synchronizations with Germany worsened in Case III and became worse than Turkey's. When Cases II and III were compared, it was observed that Italy and Czech Republic's real interest synchronizations with Germany improved in Case III and became better than Turkey's, whereas Norway, Luxembourg, and Austria's real interest rate synchronizations with Germany worsened in Case III and became worse than Turkey's. Cyclical components of real interest rates of Germany and Turkey which improved in Case III compared to Case I but worsened compared to Case II are given in Figure 7.

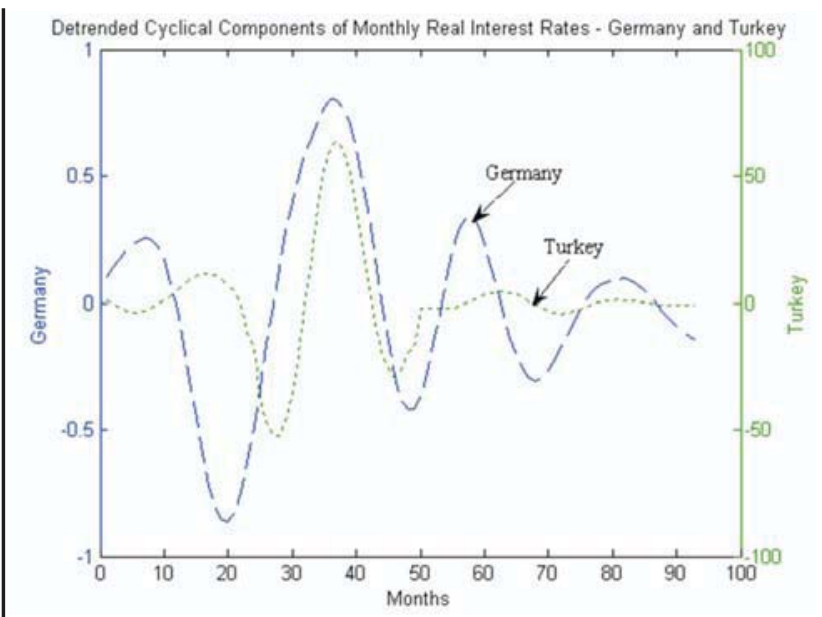

\section{Figure 7.}

Case III: Cyclical Components of Real Interest Rates of Germany and Turkey

All of these results under different filtering techniques indicate that the results are very sensitive to the filtering techniques employed. Consequently, the proper use of filtering techniques gains importance, requiring that findings be evaluated cautiously.

\subsection{OCA Similarity Matrix}

In this study, we calculated similarity measures for every country in the sample in terms of OCA criteria, taking Germany as the center country. In general, distance measures were used as similarity measures. Among these, the Euclidian distance measure was the most widely used:

Let $y_{i}=\left(y_{i 1} \ldots, y_{i 5}\right)$ be a vector of OCA criteria for country $i$, where, $i=1, \ldots, 27$,

$y_{i l}=$ synchronization in business cycles, $y_{i 2}=$ volatility in the real exchange rates,

$y_{i 3}=$ synchronization in the real interest rates, $y_{i 4}=$ the degree of trade integration, 
$y_{i 5}=$ convergence of inflation, and OCAdata matrix, $Y=\left(Y_{1}^{\top}\right.$, $Y_{2}^{\top}, \ldots . ., Y_{27}^{\top}$ ).

The Euclidian distance between country $i$ and country $j$ is given as:

$$
\operatorname{Dist}_{\text {Buclidian }}\left(y_{i}, y_{j}\right)=\sqrt{\left(y_{i}-y_{j}\right)^{T}\left(y_{i}-y_{j}\right)}
$$

A drawback of this measure is that if the mean of any one of the variables is higher than the others, this variable dominates the similarity measure. In order to neutralize this effect, two methodologies have been widely used in literature. In the first one, variables are standardized as in Artis and Zhang (2002), Boreiko (2002), and Kozluk (2005). In the second, Mahalanobis distance has been used (Mahalanobis (1936)). Mahalanobis distance between country i and country $\mathrm{j}$ is given by:

$$
\operatorname{Dist}_{\text {Mahalanobs }}\left(y_{i}, y_{j}\right)=\sqrt{\left(y_{i}-y_{j}\right)^{T} \Sigma^{-1}\left(y_{i}-y_{j}\right)}
$$

where $\Sigma$ is the covariance matrix of $Y$. The OCA similarity (distance) matrix can be written as:

$$
D=\left[\begin{array}{cccc}
d_{1,1} & d_{1,2} & \ldots & d_{1,27} \\
d_{2,1} & d_{2,2} & \ldots & d_{2,27} \\
\ldots & \ldots & \ldots & \ldots \\
d_{27,1} & d_{27,2} & \ldots & d_{27,27}
\end{array}\right]
$$

where $d_{i, j}$ is the similarity measure between country $i$ and country $j$. The OCA similarity matrix for Case III is given in Appendix B.

\section{Result}

Table 5 shows the similarity values of each country with respect to the center country, Germany, for all three cases.

\begin{tabular}{|l|l|l|l|l|l|}
\hline \multicolumn{3}{|c}{ CASE I } & \multicolumn{4}{|c}{ CASE II } & \multicolumn{2}{c}{ CASE III } \\
\hline Denmark & 1.68 & Austria & 1.28 & Denmark & 1.70 \\
\hline Austria & 1.73 & Denmark & 1.67 & Austria & 2.09 \\
\hline Italy & 1.81 & Belgium & 1.79 & Italy & 2.19 \\
\hline Spain & 1.89 & Finland & 1.81 & Spain & 2.30 \\
\hline Finland & 2.16 & Spain & 1.91 & Slovenia & 2.44 \\
\hline Belgium & 2.19 & France & 1.91 & Hungary & 2.63 \\
\hline Slovenia & 2.22 & Italy & 2.04 & Greece & 2.69 \\
\hline France & 2.24 & Slovenia & 2.28 & Finland & 2.72 \\
\hline Luxembourg & 2.49 & Luxembourg & 2.42 & Belgium & 2.74 \\
\hline Greece & 2.50 & Netherlands & 2.45 & Czech Republic & 2.84 \\
\hline United Kingdom & 2.56 & Sweden & 2.62 & Poland & 3.13 \\
\hline Sweden & 2.59 & Ireland & 2.70 & United Kingdom & 3.19 \\
\hline Netherlands & 2.67 & United Kingdom & 2.70 & Sweden & 3.20 \\
\hline Ireland & 2.83 & Poland & 2.95 & Ireland & 3.39 \\
\hline Poland & 2.92 & Greece & 3.07 & France & 3.42 \\
\hline Cyprus & 3.35 & Cyprus & 3.32 & Luxembourg & 3.49 \\
\hline Hungary & 3.40 & Canada & 3.77 & Slovak Republic & 3.54 \\
\hline Canada & 3.76 & Hungary & 3.87 & Netherlands & 3.63 \\
\hline Czech Republic & 3.78 & Slovak Republic & 3.88 & Canada & 3.78 \\
\hline Portugal & 4.19 & Portugal & 4.09 & Cyprus & 4.05 \\
\hline Slovak Republic & 4.21 & Czech Republic & 4.28 & Croatia & 4.17 \\
\hline Norway & 4.29 & Norway & 4.29 & Portugal & 4.58 \\
\hline Romania & 4.48 & Romania & 4.45 & Turkey & 4.89 \\
\hline Japan & 4.64 & Japan & 4.53 & Japan & 5.04 \\
\hline Turkey & 4.81 & Turkey & 4.79 & Norway & 5.04 \\
\hline Croatia & 4.83 & Croatia & 4.85 & Romania & 5.09 \\
\hline
\end{tabular}

Table 5.

Similarities with Respect to Germany ${ }^{\mathrm{a}}$

a This table has been derived from OCA Similarity Matrices

for Cases I, II and III. OCA Similarity Matrix for Case III is

given in Table B-1 in Appendix B.

According to Table 5, in Case I, the nearest neighbor of Germany was Denmark and the furthest neighbor is Croatia. Turkey was the second furthest neighbor of Germany after Croatia. In Case II, the nearest neighbor of Germany was Austria, and the furthest neighbor was again Croatia. Similarly, Turkey was the second furthest neighbor of Germany after Croatia. In Case III, the nearest neighbor of Germany was Denmark, and the furthest was Romania. Turkey became the third furthest neighbor of Germany after Norway and Romania. Again, we would like to recall our observation that the results are highly sensitive to the filtering techniques employed, requiring that findings be evaluated cautiously. 
In order to assess the relative position of the control group, we carried out principal component analysis.

\begin{tabular}{|l|c|c|c|}
\hline & \multicolumn{3}{|c|}{ Variability Explained (\%) } \\
\hline & CASE I & CASE II & CASE III \\
\hline $1^{\text {st }}$ Principal Component & 38.13 & 35.88 & 33.56 \\
\hline $2^{\text {nd }}$ Principal Component & 63.12 & 60.87 & 58.70 \\
\hline $3^{\text {rd }}$ Principal Component & 82.05 & 80.84 & 77.59 \\
\hline $4^{\text {th }}$ Principal Component & 93.95 & 93.79 & 93.76 \\
\hline $5^{\text {th }}$ Principal Component & 100 & 100 & 100 \\
\hline
\end{tabular}

\section{Table 6.}

Principal Component Analysis

Table 6 illustrates that the first three principal components explain almost 80 percent of the variability in data for all cases. The relative position of the control group countries could have been observed in three dimensional figures but we preferred, for the sake of clarity, to present the projection of these data in two dimensional figures, as the distances between data points in three dimensional figures are difficult to interpret.

\begin{tabular}{|c|c|c|c|c|c|c|c|c|}
\hline Austria & Slovenia & 0.77 & Belgium & 0.79 & Hungary & 1.13 & Turkey & 4.58 \\
\hline Belgium & Slovenia & 0.68 & Austria & 0.79 & Hungary & 0.79 & Turkey & 4.22 \\
\hline Croatia & United Kingdom & 1.45 & Netherlands & 1.76 & France & 1.82 & Turkey & 3.90 \\
\hline Cyprus & Italy & 1.92 & Portugal & 1.99 & Spain & 2.07 & Turkey & 5.13 \\
\hline Czech Republic & Luxembourg & 1.16 & Sweden & 1.18 & Poland & 1.28 & Turkey & 4.24 \\
\hline Denmark & Italy & 1.05 & Spain & 1.34 & Czech Republic & 1.45 & Turkey & 4.51 \\
\hline Finland & Slovenia & 0.29 & Belgium & 1.25 & Austria & 1.34 & Turkey & 4.83 \\
\hline France & Netherlands & 0.29 & Ireland & 0.50 & United Kingdom & 1.39 & Turkey & 4.92 \\
\hline Germany & Denmark & 1.70 & Austria & 2.09 & Italy & 2.19 & Turkey & 4.89 \\
\hline Greece & Ireland & 1.42 & United Kingdom & 1.43 & Slovenia & 1.60 & Turkey & 4.54 \\
\hline Hungary & Belgium & 0.79 & Austria & 1.13 & Slovenia & 1.18 & Turkey & 3.59 \\
\hline Ireland & France & 0.50 & Netherlands & 0.68 & United Kingdom & 1.20 & Turkey & 4.76 \\
\hline Italy & Spain & 0.96 & Denmark & 1.05 & Cyprus & 1.92 & Turkey & 4.62 \\
\hline Luxembourg & Czech Republic & 1.16 & Netherlands & 1.37 & France & 1.45 & Turkey & 4.43 \\
\hline Netherlands & France & 0.29 & Ireland & 0.68 & Portugal & 1.24 & Turkey & 4.93 \\
\hline Norway & Sweden & 2.14 & Poland & 2.22 & Czech Republic & 2.42 & Turkey & 4.43 \\
\hline Poland & Czech Republic & 1.28 & Sweden & 1.59 & Denmark & 2.06 & Turkey & 3.73 \\
\hline Portugal & Netherlands & 1.24 & France & 1.45 & Luxembourg & 1.49 & Turkey & 5.30 \\
\hline Romania & Greece & 3.33 & Ireland & 3.48 & Croatia & 3.59 & Turkey & 3.78 \\
\hline Slovak Republic & Belgium & 0.89 & Hungary & 1.29 & Slovenia & 1.48 & Turkey & 4.53 \\
\hline Slovenia & Belgium & 0.68 & Austria & 0.77 & Finland & 1.12 & Turkey & 4.39 \\
\hline Spain & Italy & 0.96 & Denmark & 1.34 & Cyprus & 2.07 & Turkey & 4.58 \\
\hline Sweden & Czech Republic & 1.18 & Poland & 1.59 & Denmark & 1.73 & Turkey & 4.62 \\
\hline Turkey & Romania & 4.48 & Romania & 4.48 & Romania & 3.78 & Turkey & 0 \\
\hline United Kingdom & Hungary & 3.59 & Poland & 3.73 & France & 1.39 & Turkey & 4.03 \\
\hline Canada & Japan & 3.03 & Italy & 3.05 & United Kingdom & 3.19 & Turkey & 4.47 \\
\hline Japan & United Kingdom & 2.95 & Canada & 3.03 & Finland & 3.22 & Turkey & 5.29 \\
\hline
\end{tabular}

\section{Table 7.}

The Three Nearest Neighbors and Turkey's Similarity (distance)a, Case III

a This table has been derived from 27 × 27 OCA Similarity Matrix, Case III, Table B-1 given in Appendix B.
In Figures 8 and 10 Canada and Japan can be distinguished from the European countries. Similarly, Turkey and Romania are also observed as a different group.

Table 7 shows each country's three nearest neighbors, and Turkey's distance (similarity) to each country in the sample for Case III. For Cases I and II, principal components figures, OCA similarity matrices, the three nearest neighbors of the countries and Turkey's similarity (distance) are available from the authors upon request.

The three nearest neighbors of Turkey are Hungary, Poland and Romania with quite low similarities. The higher is the OCA similarity value in Table 7, the lower is the similarity. Turkey, Romania, Canada, Japan, Norway and Cyprus exhibit low similarities to their nearest neighbors. Canada and Japan are the control group countries, and they exhibit low similarities to their nearest neighbors as expected. The other countries' low similarities might be explained by the fact that Turkey launched its EU accession negotiations in 
October 2005, Romania joined EU in January 2007, and Norway is not a European Union member, whereas Cyprus became a full member in May 2004. Therefore, this might be a sign of the endogeneity of OCA criteria. As Frankel and Rose (1996) have asserted: "Countries which join the EMU, no matter what their motivation, may satisfy OCA criteria ex

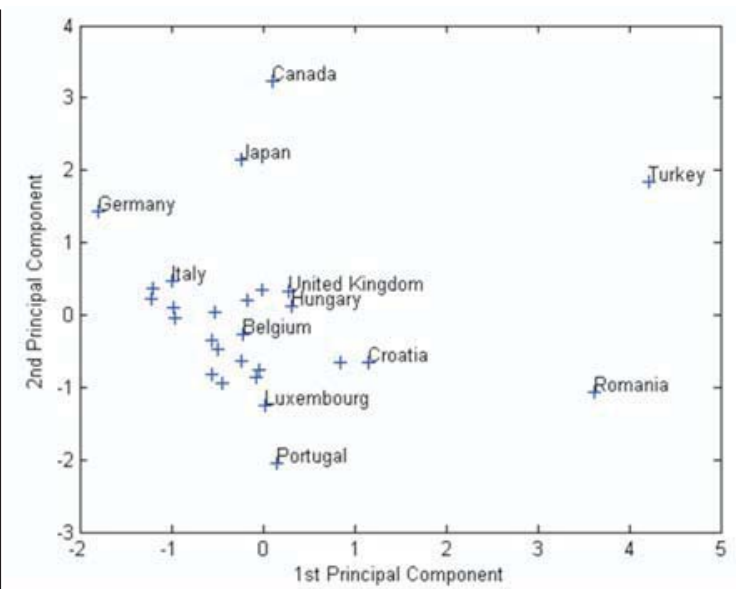

Figure 8.

Case III: 1st and 2nd Principal Components

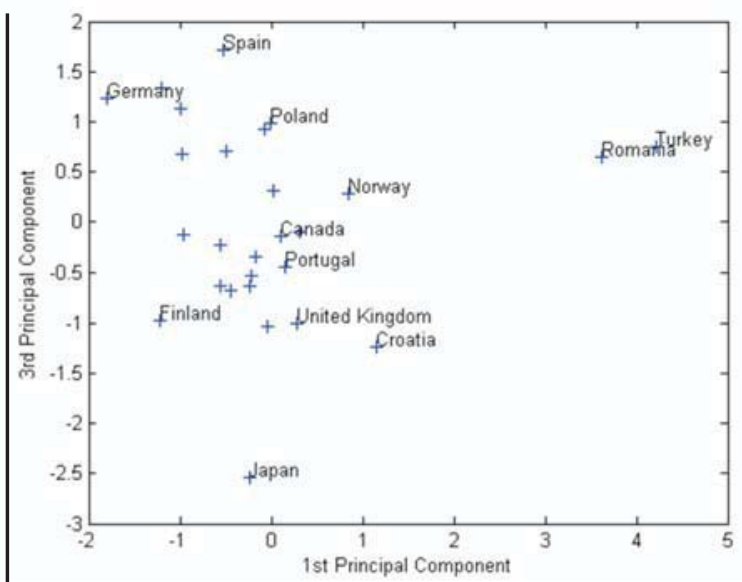

Figure 9.

Case III: $1^{\text {st }}$ and $3^{\text {rd }}$ Principal Components

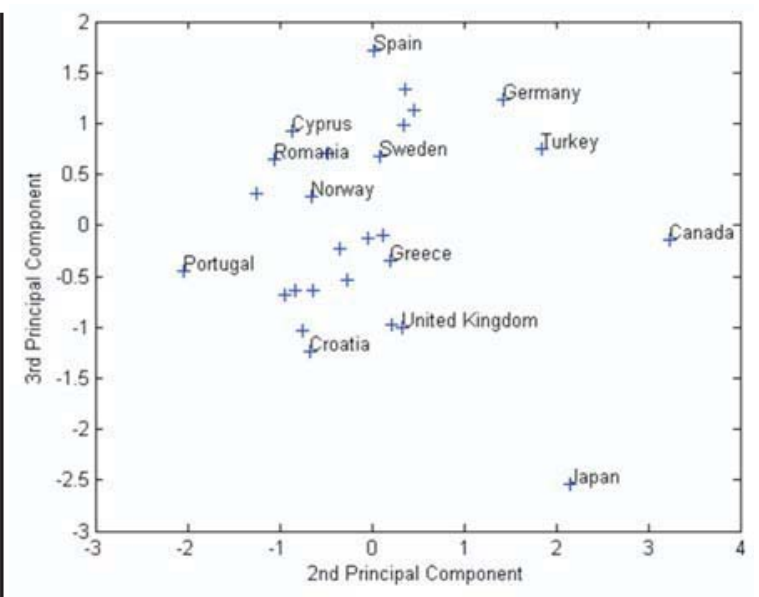

Figure 10.

Case III: $2^{\text {nd }}$ and $3^{\text {rd }}$ Principal Components post even if they do not ex ante!" (Frankel and Rose 1996, p. 3).

Surprisingly, despite the geographic proximity of the UK and Ireland, Ireland's nearest neighbor is France. UK is the third nearest neighbor of Ireland with very little difference in similarity. The nearest neighbor of the UK is Ireland and France's nearest neighbor is the Netherlands.

\section{Conclusion}

Integration efforts in Europe started in the 1950s, and the OCA theory has played an important role in deepening this process by not only providing a theoretical framework for the Economic and Monetary Union, but also by being the driving force with the empirical studies carried out aiming to operationalize the theory. During the last decades, considerable progress has been experienced in the techniques of data analysis and modelling. These include pattern recognition techniques, which have been applied widely in the literature from the natural to social sciences. Cluster analysis is a part of pattern recognition technique, and similarity measures are the key elements of cluster analysis. In this study, our aim was to evaluate the relative position of Turkey with respect to European countries. Therefore, cluster analysis was left out of the scope of this paper for future work. We followed a novel approach in the application of the Hodrick-Prescott ( $\mathrm{H}-\mathrm{P})$ and the Baxter-King (B-K) filters to monthly industrial production series and the real interest rates. After that, we employed Mahalanobis distance as a similarity measure to these widely used OCA criteria in the literature. We then created OCA similarity indices, computed countries' similarities with respect to Germany, their nearest neighbours and Turkey's similarity (distance) to these countries and to Germany. Afterwards, we compared the results. To our knowledge, this is the first analysis in this area that uses the filtering techniques as applied in Cases II and III. We included Canada and Japan as control group countries to assess the reliability of the results; indeed, our analysis did produce nonsensical results.

Our results show that Turkey is the second furthest neighbor country to Germany after Croatia in Cases I and II. However, Turkey is the third furthest country after Norway and Romania in Case III. The nearest neighbors of Turkey are Romania, Poland, and United Kingdom in Case I, Romania, Poland, and Belgium in Case II, and Hungary, Poland, and Romania in Case III. Therefore, this analysis shows that the 
results are sensitive to the filtering technique employed.

Turkey experienced two currency crises in 1994 and 2001. For this reason, it is reasonable to expect Turkey's data to be affected adversely because of these currency crises. This was clearly seen in the results. Since Turkey started EU accession negotiations recently, it has not fully benefited from the accession stage yet. Both in the accession stage and the full membership, the probability of experiencing a currency crisis as in 1994 and 2001 is very low. Therefore, Turkey will be on its path to convergence in accordance with the OCA theory. We believe that one of the factors that play a very important role in this convergence is the young and dynamic population of Turkey, which makes the Turkish economy highly adaptive. 


\section{Appendices}

\section{Appendix A}

\section{OCA Variables}

\begin{tabular}{|l|l|l|l|}
\hline Variables & Frequency & Data Sources & Time Interval \\
\hline Industrial production series & monthly & IFS & $1996: 1-2005: 6$ \\
\hline Real exchange rates & monthly & IFS, TURKSTAT & $1991: 1-2006: 12$ \\
\hline Real interest rates & monthly & $\begin{array}{l}\text { IFS, EUROSTAT, } \\
\text { Central Bank of Luxembourg }\end{array}$ & $\begin{array}{l}1997: 2-2006: 10(H-P \text { Filter }) \\
1996: 2-2005: 10(B-K \text { Filter })\end{array}$ \\
\hline Trade data & annual & UNCTAD; & 2004 \\
\hline Inflation data & annual & WDI & 2005 \\
\hline
\end{tabular}

Table A-1.

Frequency, Data Sources and the Time Interval of the OCA Variables

\begin{tabular}{|l|l|l|l|}
\hline Austria & : Government Bond Yield & Netherlands & : Government Bond Yield \\
\hline Belgium & $:$ Government Bond Yield & Norway & \\
\hline Croatia & $:$ Money Market Rate & Poland & $:$ Money Market Rate \\
\hline Cyprus & $:$ Deposit Rate & Portugal & $:$ Money Market Rate \\
\hline Czech Republic & $:$ Money Market Rate & Romania & $:$ NBR Structural Credit Rate \\
\hline Denmark & $:$ Call Money Rate & Slovak Republic & $:$ Average Lending Rate \\
\hline Finland & $:$ Government Bond Yield & Slovenia & $:$ Money Market Rate \\
\hline France & $:$ Government Bond Yield & Spain & $:$ Call Money Rate \\
\hline Germany & $:$ Call Money Rate & Sweden & $:$ Call Money Rate \\
\hline Greece & $:$ Government Bond Yield & Turkey & $:$ Interbank Money Market Rate \\
\hline Hungary & $:$ Treasury Bill Rate & United Kingdom & $:$ Government Bond Yield \\
\hline Ireland & $:$ Government Bond Yield & Canada & $:$ Bank Rate \\
\hline Italy & $:$ Money Market Rate & Japan & $:$ Govenment Bond Yield \\
\hline Luxembourg & $:$ Government Bond Yield & & \\
\hline
\end{tabular}

Table A-2.

Interest Rates 


\begin{tabular}{|l|l|l|l|l|l|l|}
\hline AT & Austria & DE & Germany & PL & Poland & UKited Kingdom \\
\hline BE & Belgium & GR & Greece & PT & Portugal & CA \\
\hline HR & Croatia & HU & Hungary & RO & Romania & JP \\
\hline CY & Cyprus & IE & Ireland & SK & Slovak Republic \\
\hline CZ & Czech Republic & IT & Italy & SI & Slovenia \\
\hline DK & Denmark & LU & Luxembourg & ES & Spain \\
\hline FI & Finland & NL & Netherlands & SE & Sweden \\
\hline FR & France & NO & Norway & TR & Turkey \\
\hline
\end{tabular}

\begin{tabular}{|l|l|l|l|l|l|l|l|l|l|l|l|l|l|l|l|l|l|l|l|l|l|l|l|l|l|l|l|l|l|l|l|l|l|l|l|l|l|l|l|l|l|l|l|}
\hline AT & BE & HR & CY & CZ & DK & FI & FR & DE & GR & HU & IE & IT & LU & NL & NO & PL & PT & RO & SK & SI & ES & SE & TR & UK & CA & JP \\
\hline
\end{tabular}

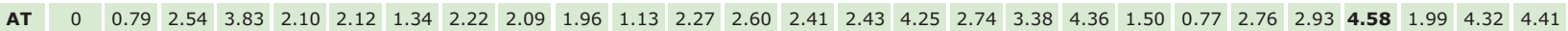
\begin{tabular}{|l|l|l|l|l|l|l|l|l|l|l|l|l|l|l|l|l|l|l|l|l|l|l|l|l|l|l|l|l|l|l|}
\hline BE & 0.79 & 0 & 1.82 & 3.76 & 2.04 & 2.48 & 1.25 & 1.98 & 2.74 & 1.99 & 0.79 & 2.03 & 2.85 & 2.14 & 2.14 & 3.87 & 2.65 & 3.03 & 4.03 & 0.89 & 0.68 & 3.04 & 2.90 & 4.22 & 1.58 & 4.33 & 4.09 \\
\hline
\end{tabular}

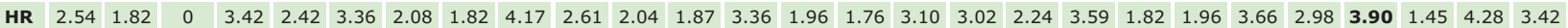
\begin{tabular}{|l|l|l|l|l|l|l|l|l|l|l|l|l|l|l|l|l|l|l|l|l|l|l|l|l|l|l|l|l|l|l|l|} 
CY & 3.83 & 3.76 & 3.42 & 0 & 2.74 & 2.68 & 3.54 & 2.25 & 4.05 & 3.04 & 3.91 & 2.24 & 1.92 & 2.11 & 2.17 & 3.67 & 3.69 & 1.99 & 3.72 & 4.37 & 3.18 & 2.07 & 2.61 & 5.13 & 3.08 & 3.86 & 4.69 \\
\hline
\end{tabular}

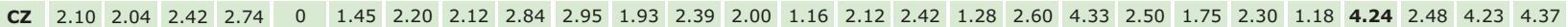
\begin{tabular}{|l|l|l|l|l|l|l|l|l|l|l|l|l|l|l|l|l|l|l|l|l|l|l|l|l|l|l|l|l|l|l|} 
DK & 2.12 & 2.48 & 3.36 & 2.68 & 1.45 & 0 & 2.43 & 2.50 & 1.70 & 2.62 & 2.37 & 2.60 & 1.05 & 2.10 & 2.61 & 3.61 & 2.06 & 3.31 & 4.47 & 3.24 & 1.99 & 1.34 & 1.73 & 4.51 & 2.74 & 3.65 & 4.65 \\
\hline
\end{tabular}

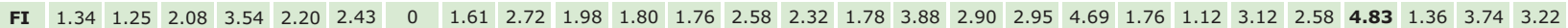
\begin{tabular}{|l|l|l|l|l|l|l|l|l|l|l|l|l|l|l|l|l|l|l|l|l|l|l|l|l|l|l|l|l|l|} 
FR & 2.22 & 1.98 & 1.82 & 2.25 & 2.12 & 2.50 & 1.61 & 0 & 3.42 & 1.80 & 2.48 & 0.50 & 2.20 & 1.45 & 0.29 & 3.58 & 3.23 & 1.45 & 3.81 & 2.45 & 1.50 & 2.60 & 2.46 & 4.92 & 1.39 & 3.85 & 3.60 \\
\hline
\end{tabular}

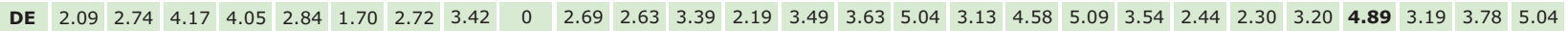
\begin{tabular}{|l|l|l|l|l|l|l|l|l|l|l|l|l|l|l|l|l|l|l|l|l|l|l|l|l|l|l|l|l|l|l|l|}
\hline GR & 1.96 & 1.99 & 2.61 & 3.04 & 2.95 & 2.62 & 1.98 & 1.80 & 2.69 & 0 & 2.34 & 1.42 & 2.27 & 2.66 & 2.05 & 4.83 & 3.80 & 2.97 & 3.33 & 2.74 & 1.60 & 2.37 & 3.48 & 4.54 & 1.43 & 3.41 & 4.06 \\
\hline
\end{tabular} \begin{tabular}{|l|l|l|l|l|l|l|l|l|l|l|l|l|l|l|l|l|l|l|l|l|l|l|l|l|l|l|l|l|l|l|l|l|l|l|l|l|}
\hline HU & 1.13 & 0.79 & 2.04 & 3.91 & 1.93 & 2.37 & 1.80 & 2.48 & 2.63 & 2.34 & 0 & 2.50 & 2.87 & 2.28 & 2.61 & 3.68 & 2.21 & 3.40 & 3.93 & 1.29 & 1.18 & 2.99 & 2.84 & 3.59 & 1.91 & 4.27 & 4.29 \\
\hline
\end{tabular} \begin{tabular}{|l|l|l|l|l|l|l|l|l|l|l|l|l|l|l|l|l|l|l|l|l|l|l|l|l|l|l|l|l|l|l|l|} 
IE & 2.27 & 2.03 & 1.87 & 2.24 & 2.39 & 2.60 & 1.76 & 0.50 & 3.39 & 1.42 & 2.50 & 0 & 2.19 & 1.72 & 0.68 & 3.87 & 3.44 & 1.65 & 3.48 & 2.58 & 1.57 & 2.52 & 2.76 & 4.76 & 1.20 & 3.65 & 3.61 \\
\hline
\end{tabular}

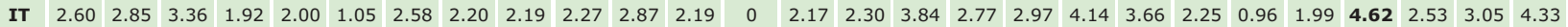
\begin{tabular}{l|l|l|l|l|l|l|l|l|l|l|l|l|l|l|l|l|l|l|l|l|l|l|l|l|l|l|l|l|l|l|} 
LU & 2.41 & 2.14 & 1.96 & 2.11 & 1.16 & 2.10 & 2.32 & 1.45 & 3.49 & 2.66 & 2.28 & 1.72 & 2.17 & 0 & 1.37 & 2.59 & 2.30 & 1.49 & 3.67 & 2.52 & 1.76 & 2.34 & 1.81 & 4.43 & 2.21 & 4.38 & 4.36 \\
\hline
\end{tabular}

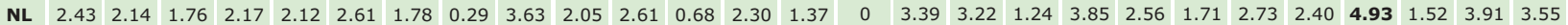
\begin{tabular}{|l|l|l|l|l|l|l|l|l|l|l|l|l|l|l|l|l|l|l|l|l|l|l|l|l|l|l|l|l|l|l|l|l|}
\hline NO & 4.25 & 3.87 & 3.10 & 3.67 & 2.42 & 3.61 & 3.88 & 3.58 & 5.04 & 4.83 & 3.68 & 3.87 & 3.84 & 2.59 & 3.39 & 0 & 2.22 & 3.32 & 5.28 & 3.95 & 3.80 & 4.24 & 2.14 & 4.43 & 3.83 & 5.05 & 4.48 \\
\hline
\end{tabular}

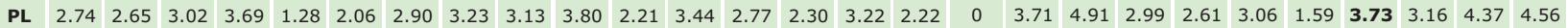
\begin{tabular}{|l|l|l|l|l|l|l|l|l|l|l|l|l|l|l|l|l|l|l|l|l|l|l|l|l|l|l|l|l|l|l|l|l|l|l|} 
PT & 3.38 & 3.03 & 2.24 & 1.99 & 2.60 & 3.31 & 2.95 & 1.45 & 4.58 & 2.97 & 3.40 & 1.65 & 2.97 & 1.49 & 1.24 & 3.32 & 3.71 & 0 & 3.70 & 3.27 & 2.65 & 3.17 & 2.88 & 5.30 & 2.57 & 4.77 & 4.41 \\
\hline
\end{tabular}

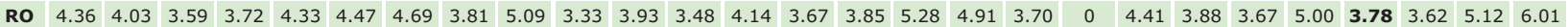
\begin{tabular}{|l|l|l|l|l|l|l|l|l|l|l|l|l|l|l|l|l|l|l|l|l|l|l|l|l|l|l|l|l|l|l|} 
SK & 1.50 & 0.89 & 1.82 & 4.37 & 2.50 & 3.24 & 1.76 & 2.45 & 3.54 & 2.74 & 1.29 & 2.58 & 3.66 & 2.52 & 2.56 & 3.95 & 2.99 & 3.27 & 4.41 & 0 & 1.48 & 3.85 & 3.38 & 4.53 & 2.13 & 5.05 & 4.34 \\
\hline
\end{tabular}

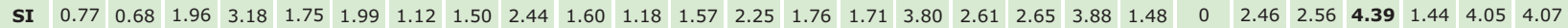
\begin{tabular}{|l|l|l|l|l|l|l|l|l|l|l|l|l|l|l|l|l|l|l|l|l|l|l|l|l|l|l|l|l|l|l|l|} 
ES & 2.76 & 3.04 & 3.66 & 2.07 & 2.30 & 1.34 & 3.12 & 2.60 & 2.30 & 2.37 & 2.99 & 2.52 & 0.96 & 2.34 & 2.73 & 4.24 & 3.06 & 3.17 & 3.67 & 3.85 & 2.46 & 0 & 2.62 & 4.58 & 2.95 & 3.67 & 5.14 \\
\hline
\end{tabular} \begin{tabular}{|l|l|l|l|l|l|l|l|l|l|l|l|l|l|l|l|l|l|l|l|l|l|l|l|l|l|l|l|l|l|l|l|} 
SE & 2.93 & 2.90 & 2.98 & 2.61 & 1.18 & 1.73 & 2.58 & 2.46 & 3.20 & 3.48 & 2.84 & 2.76 & 1.99 & 1.81 & 2.40 & 2.14 & 1.59 & 2.88 & 5.00 & 3.38 & 2.56 & 2.62 & 0 & 4.62 & 2.87 & 3.82 & 3.95 \\
\hline
\end{tabular} \begin{tabular}{|l|l|l|l|l|l|l|l|l|l|l|l|l|l|l|l|l|l|l|l|l|l|l|l|l|l|l|l|l|l|} 
TR & 4.58 & 4.22 & 3.90 & 5.13 & 4.24 & 4.51 & 4.83 & 4.92 & 4.89 & 4.54 & 3.59 & 4.76 & 4.62 & 4.43 & 4.93 & 4.43 & 3.73 & 5.30 & 3.78 & 4.53 & 4.39 & 4.58 & 4.62 & 0 & 4.03 & 4.47 & 5.29 \\
\hline
\end{tabular}

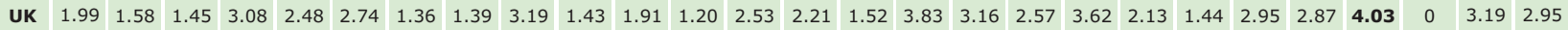
\begin{tabular}{|l|l|l|l|l|l|l|l|l|l|l|l|l|l|l|l|l|l|l|l|l|l|l|l|l|l|l|l|l|l|l|}
\hline CA & 4.32 & 4.33 & 4.28 & 3.86 & 4.23 & 3.65 & 3.74 & 3.85 & 3.78 & 3.41 & 4.27 & 3.65 & 3.05 & 4.38 & 3.91 & 5.05 & 4.37 & 4.77 & 5.12 & 5.05 & 4.05 & 3.67 & 3.82 & 4.47 & 3.19 & 0 & 3.03 \\
\hline
\end{tabular} \begin{tabular}{|l|l|l|l|l|l|l|l|l|l|l|l|l|l|l|l|l|l|l|l|l|l|l|l|l|l|l|l|l|l|l} 
JP & 4.41 & 4.09 & 3.42 & 4.69 & 4.37 & 4.65 & 3.22 & 3.60 & 5.04 & 4.06 & 4.29 & 3.61 & 4.33 & 4.36 & 3.55 & 4.48 & 4.56 & 4.41 & 6.01 & 4.34 & 4.07 & 5.14 & 3.95 & 5.29 & 2.95 & 3.03 & 0
\end{tabular}

Table B-1.

OCA Similarity Matrix, Case III

${ }^{a}$ This matrix has been calculated by Mahalanobis distance function employed in Matlab. 


\section{References}

Artis, M. J. and Zhang, W. (2001), "Core and Periphery in EMU: A Cluster Analysis,” Economic Issues, 6(2), 3960.

Artis, M. J. and Zhang, W. (2002), "Membership of EMU: A Fuzzy Clustering Analysis of Alternative Criteria," Journal of Economic Integration, 17(1), 54-79.

Baxter, M. and King, R. G. (1999), "Measuring business cycles: Approximate band-pass filters," The Review of Economics and Statistics, 81(4), 575-93.

Burns, A. F. and Mitchell, W. C. (1946), Measuring Business Cycles, New York: NBER.

Boreiko, D. (2002), "EMU and Accession Countries: Fuzzy Cluster Analysis of Membership," Oesterreichische Nationalbank Working Paper No. 71.

Dermoune, A., Djehiche, B. and Rahmania, N. (2006), "Consistent estimators of the smoothing parameter in the Hodrick-Prescott filter," Preprint.

Duda, R. O., Hart, P. E. and Stork, D. G. (2000), Pattern Classification, Second Edition, United States: John Wiley \& Sons.

Eichengreen, B. and Bayoumi, T. (1996), "Ever Closer to Heaven? An Optimum-Currency-Area Index for European Countries," Institute of Business and Economic Research Center for International and Development Economics Research Paper C96-078, Berkeley: University of California.

Frankel, J. A. and Rose, A. K. (1996), "The Endogeneity of the Optimum Currency Area Criteria,” NBER Working Paper No. 5700.

Guay, A. and St-Amant, P. (1997), "Do the Hodrick-Prescott and Baxter-King Filters Provide a Good Approximation of Business Cycles?" Centre de Recherche Sur l'emploi et les Fluctuations économiques (CREFÉ) Working Paper No. 53.

Hodrick, R. J. and Prescott, E. C. (1997), "Postwar U.S. business cycles: An empirical investigation," Journal of Money, Credit, and Banking, 29(1), 1-16.

Kenen, P. B. (1969), "The Theory of Optimal Currency Areas: An Eclectic View," in Monetary Problems of the International Economy, edited by R.A. Mundell and A.K. Swoboda, Chicago: University of Chicago Press, 41-60.

Komárek, L., Cech, Z. and Horváth, R. (2003), "Optimum Currency Area Indices - How Close is the Czech Re- public to the Eurozone?" The Czech National Bank Working Paper No. 10.

Kozluk, T. (2005), 'CEEC Accession Countries and the EMU: An Assessment of Relative Suitability and Readiness for Euro-Area Membership'. Journal of Economic Integration, 20(3), pp. 439-74.

Mahalanobis, P. C. (1936), "On the Generalized Distance in Statistics," Proceedings National Institute of Science, $12,49-55$.

McKinnon, R. I. (1963), “Optimum Currency Areas,” American Economic Review, 53, 717-24.

Mundell, R. A. (1961), "A Theory of Optimal Currency Areas," American Economic Review, 51, 657-65.

Murray, C. J. (2003), "Cyclical Properties of Baxter-King Filtered Time Series," The Review of Economics and Statistics, 85(2), 472-76.

Schlicht, E. (2005), "Estimating the Smoothing Parameter in the So-called Hodrick-Prescott Filter," Journal of the Japan Statistical Society, 35(1), 99-119.

Takaya, S. (2005), "Do EMU Countries Have the Same Business Cycles? - A Lesson for Regional Monetary Integration in East Asia," EUSA-AP-Japan. 